\title{
Metodología para la valoración y evaluación de geomorfositios en Costa Rica
}

\section{Methodology for evaluating and assessing geomorphosites in Costa Rica}

\author{
Dennis Pérez-Umaña ${ }^{1}$ \\ Universidad Nacional de Costa Rica \\ Adolfo Quesada-Román ${ }^{2}$ \\ Universidad de Ginebra, Suiza
}

http://dx.doi.org/10.15359/rgac.60-1.4

\section{RESUMEN}

El siguiente trabajo presenta la implementación de una metodología para la evaluación de geomorfositios en Costa Rica, tomando como área de estudio el Parque Nacional Volcán Poás. El objetivo es evaluar los geomorfositios existentes dentro de esta área silvestre protegida mediante una metodología de evaluación de geomorfositios, dicha metodología consiste en la comparación de las características científicas, culturales o añadidas y de uso y gestión presentes en el geomorfositio. Se determina que el Parque Nacional Volcán Poás tiene diversas formaciones que pueden ser consideradas como geomorfositios, además, que hay diversos valores agregados que denotan la importancia que tiene el volcán para la población costarricense. La metodología utilizada en este trabajo puede ser utilizada en otros territorios, con miras a que su implementación pueda colaborar al Ordenamiento Territorial de Costa Rica.

Palabras clave: Geositios, geomorfología, geoturismo, geoconservación, volcán Poás.

1 Licenciatura en Ciencias Geográficas con énfasis en Ordenamiento del Territorio. Escuela de Ciencias Geográficas. Correo electrónico: dennisperez09@gmail.com

2 Instituto de Ciencias Ambientales, Universidad de Ginebra (Suiza). Correo electrónico: adolfo.quesada@ gmail.com 
Dennis Pérez-Umaña,. Adolfo Quesada-Román. Methodology for evaluating and assessing geomorphosites in Costa Rica

\begin{abstract}
This paper presents the implementation of a methodology for geomorphosites assessment in Costa Rica-taking the Poás Volcano National Park as study area. The objective is to evaluate the existing geomorphosites inside this protected area using a methodology of geomorphosites assessment. This methodology consists of a comparison of scientific values, added values, and use and management values present in the geomorphosites. It is determined that the Poás Volcano National Park has diverse formations that could be considered as geomorphosites. Moreover, it has several values added that denote the importance that volcano has for Costa Rican people. The methodology used in this work can be used in other territories and can be used to contribute to Land Use Planning in Costa Rica.
\end{abstract}

Keywords: Geosites, geomorphology, geotourism, geoconservation, Poás Volcano.

\title{
Introducción
}

La superficie terrestre alberga distintas formaciones, algunas muy complejas y otras muy simples, algunas con edades recientes y otras que son muy antiguas en relación a otros relieves. Estas formaciones llegan a ser atractivas para la población, ya sea porque presentan un paisaje singular o porque lo relacionan con algún otro elemento que les genere un aprecio, es aquí, cuando una formación del relieve puede ser nombrada como geomorfositio. Comanescu y Nedelea (2010) citan a Panizza (2001), quien define un geomorfositio como una parte de la superficie terrestre que tiene importancia para entender la historia de la Tierra.

Coratza et al. (2008) señalan que un geomorfositio es un relieve que presenta atributos particulares que lo hacen parte del patrimonio cultural de un territorio, donde la población le otorga valores socioeconómicos, culturales y escénicos, reforzando la idea de Reynard y Panizza (2005), quienes habían mencionado que los valores añadidos que tiene un geomorfositio son el valor estético, histórico, cultural y socioeconómico.

Puede ser objeto geomorfológico individual hasta un paisaje, el cual puede ser modificado o destruido por la actividad humana (Palacio, 2013), por lo que son formaciones que deben ser protegidas mediante alguna regulación, donde se permitan actividades que no afecten el geomorfositio (Pereira et al., 2007, citado por Costa, 2011), ya que son relieves susceptibles a cambios en su morfología, provocados por muchos factores, agentes y procesos (Ilies y Josan, 2008).

Para valorar y evaluar un geomorfositio se deben tomar en cuenta una serie de valores, que a primera instancia no pueden establecerse mediante métodos estadísticos o ecuaciones matemáticas, ya que hay valores que no pueden ser contables, como los valores culturales de un 
geomorfositio, pero esto se puede realizar si se elabora un método, lo más objetivo posible, donde se puedan comparar todos los valores de un geomorfositio (González y Serrano, 2008).

El presente trabajo tiene como objetivo evaluar los geomorfositios del Parque Nacional Volcán Poás mediante una metodología comparativa. Cabe resaltar que este estudio fue realizado entre 2014 y 2017, anterior a la fase eruptiva actual (a partir de abril de 2017) que ha mantenido cerrado el parque nacional debido a la peligrosidad de su actividad.

\section{Área de estudio}

El Parque Nacional Volcán Poás fue creado en 1970, mediante el Decreto Ejecutivo $\mathrm{N}^{\circ} 1237$ con el objetivo de conservar los recursos naturales. En 1971, con la Ley $\mathrm{N}^{\circ} 4714$ se ratifica la creación de este (SINAC, 2008). Se localiza en la provincia de Alajuela, respectivamente, entre los cantones de Alajuela, Grecia, Poás y Valverde Vega (Mapa 1), tiene un área de 6506 hectáreas. Pérez (2017) señala que esta área silvestre protegida presenta una topografía irregular, siendo notable su variación altitudinal, donde la altitud mínima es de $1100 \mathrm{msnm}$ y su altitud máxima es de $2708 \mathrm{msnm}$.

Es el Parque Nacional volcánico más visitado de Costa Rica, ya que de acuerdo con SINAC (2016), en el año 2015 ingresaron a esta área silvestre protegida un total de 370176 visitantes, lo cual lo convierte en uno de los Parques Nacionales más importantes de Costa Rica, en materia de turismo, donde el turista ingresa atraído por sus paisajes volcánicos, su biodiversidad y sobre todo para conocer uno de los llamados erróneamente “cráteres más grandes del mundo" (Salguero, 2003).

En los alrededores de esta área silvestre protegida, la población realiza actividades agrícolas como el cultivo de fresas, helechos, entre otros (SINAC, 2008); los turistas que ascienden al volcán aprovechan para comprar algún producto o recuerdo, lo que incentiva la economía local, y se convierte en un beneficio adicional que brinda el parque nacional a la población. 
Dennis Pérez-Umaña,. Adolfo Quesada-Román. Methodology for evaluating and assessing geomorphosites in Costa Rica

Mapa 1: Área de estudio: Parque Nacional Volcán Poás

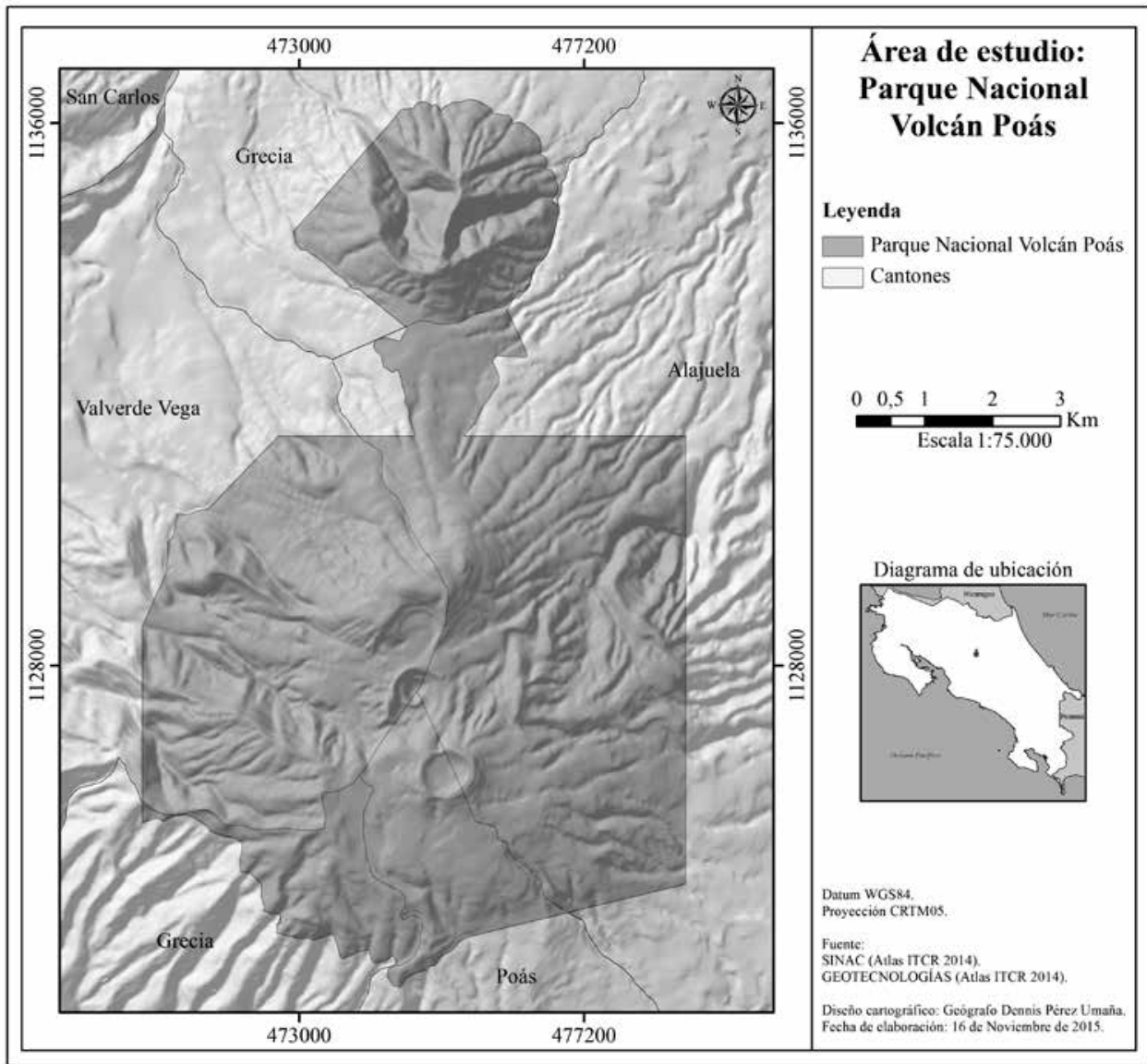

Fuente: Pérez (2017).

\section{Caracterización del área de estudio}

\section{Caracterización geofísica}

El volcán Poás es un complejo estratovolcán que posee una forma subcónica irregular (Alvarado, 2011), se localiza al noroeste de la Cordillera Volcánica Central de Costa Rica (Ruiz et al., 2010). Alvarado (2011) señala que sus principales estructuras son el Cráter Principal, el Cono Botos y el Cono Von Frantzius, los cuales se encuentran alineados en dirección sur norte, siendo evidencia de un posible vulcanismo fisural 
en el pasado del macizo (Ruiz et al., 2010), aunque Pérez (2017) sugiere que dichas estructuras son producto del desplazamiento del foco eruptivo en el pasado.

Dentro del Parque Nacional Volcán Poás se localiza también el Volcán Congo, otra estructura que también está alineada junto con los demás conos del volcán Poás. El Volcán Congo tiene una forma cónica bien desarrollada, cuyas laderas están cubiertas por lavas emitidas por el Cono Von Frantzius (Ruiz et al., 2010). Alvarado y Salani (2004) indican que este volcán tiene dos aberturas en direcciones noroeste y noreste creadas durante su último periodo eruptivo.

El Cráter Principal es una de las estructuras más jóvenes de este volcán, ya que cuenta con una edad de 3500 años, mientras que los Conos Botos y Von Frantzius son más antiguos con edades de 8300 y 46000 años, respectivamente (Ruiz et al., 2010). El origen de este cráter tuvo como consecuencia que la mitad del Cono Von Frantzius se destruyera (Pérez, 2017). Por otra parte, el Cono Von Frantzius también es susceptible a movimientos de ladera, ya que, durante el Terremoto de Cinchona del año 2009, distintos movimientos de ladera se dieron en este cono (Quesada y Barrantes, 2016).

El Cono Botos se localiza al sur del Cráter Principal y su principal característica es la laguna pluvial localizada en su interior, la cual tiene un diámetro de 400 metros y una profundidad de 14 metros (Alvarado, 2011). Dicha laguna tiene una gran importancia hídrica, ya que sus aguas drenan por el río Ángel, que es una de las nacientes del río Sarapiquí (Vargas, 2014).

\section{Caracterización cultural.}

El volcán Poás ha tenido un papel muy importante en la cultura costarricense, ya que ha sido la inspiración para escritores, músicos, cuentistas y demás (Pérez, 2017). Cabe señalar que algunas obras literarias mencionan al Cráter Principal como parte de sus narrativas, se puede señalar el poema "El Volcán Poás" de Carlomagno Araya y el verso "Semblanza del volcán Poás" de Alfredo Cardona Peña, así como la leyenda del "Sacrificio del Rualdo" (Alvarado, 2011), también una versión alternativa de la leyenda del Cadejos (Zeledón, 1989).

En la música se destacan dos obras, la "Sinfonía de los Volcanes", compuesta en 2008 por el compositor costarricense Carlos Guzmán, donde 
uno de los movimientos de esta obra recibe el nombre del volcán Poás (Alvarado, 2013). La otra canción es "A la sombra del Poás", escrita por Mario Jinesta, la cual habla acerca de las tradiciones de la población alajuelense, así como de personajes históricos importantes y sitios icónicos de Alajuela (Chaves, 2014).

Imágenes del volcán Poás han sido parte de billetes, como señala Alvarado (2013), en el billete de 20 colones de 1945 aparece una imagen del volcán Poás con una erupción freática, así como en el billete de 10 mil colones de 1997, el cual tiene ilustraciones de 4 volcanes, siendo el Poás uno de estos. También apareció en una estampilla de 140 colones una imagen del Cráter Principal junto con la Laguna Botos (Pérez, 2017).

También a nivel cultural, se destacan los nombres que reciben las principales estructuras el volcán. El término Poás surge en 1663 como referencia a la existencia de plantas con púas a las orillas del río Poás, llamado en aquel entonces río Púas (Alvarado, 2011), pero Ceruti (2010) rescata que el nombre aborigen de este volcán era "Chibuzú", palabra de origen Huetar cuyo significado es "Montaña del Dios". Lo mismo sucede con los nombres de los Conos Botos y Von Frantzius, el primero que recibe el nombre en honor a los indígenas Botos (Ceruti, 2010), mientras que el segundo recibe su nombre en honor a Alexander Von Frantzius, uno de los primeros naturalistas que ascendió al volcán a realizar estudios científicos (Vargas, 2014).

Este tipo de características, tanto geofísicas como culturales, son las que dan valor a los geomorfositios, además, son parte de los valores que se toman en cuenta en la evaluación. Son estas características las que hacen atractivos a los geomorfositios y las que se utilizan para promover el turismo para estos relieves.

\section{Metodología}

En primera instancia, en una etapa preliminar se hizo un levantamiento de la geomorfología del Parque Nacional Volcán Poás, donde se definieron los geomorfositios presentes dentro de esta área silvestre protegida. Con base a esto, se puso en práctica una metodología de evaluación de geomorfositios. La metodología utilizada en este trabajo corresponde a la elaborada por Serrano y González (2005), la cual consiste en una comparación triple de los diferentes valores presentes en los geomorfositios. 
La primera evaluación, es la de las características científicas, que corresponden a toda la información de índole geológica y geomorfológica de los geomorfositios, donde se enumeran las formas presentes y los elementos que han intervenido en su origen (González, 2006), estos valores se cuantifican del 1 al 10 en cada categoría, teniendo una sumatoria máxima de 100, y para compararlo con las otras evaluaciones se pondera de 0 a 10 (De Jesús, 2014). En la Tabla 1, se muestran los componentes de esta evaluación.

Tabla 1: Componentes de la evaluación de las características científicas de los geomorfositios

\begin{tabular}{|c|c|c|c|}
\hline \multicolumn{2}{|c|}{ Evaluación } & Puntos & Definición \\
\hline \multicolumn{2}{|l|}{ Génesis } & \multirow{10}{*}{ Máximo 10} & $\begin{array}{l}\text { Procesos que han intervenido en la } \\
\text { formación }\end{array}$ \\
\hline \multirow{3}{*}{ Morfología } & Morfoestructuras & & \multirow{3}{*}{$\begin{array}{l}\text { Número de relieves que conforman } \\
\text { el geomorfositio }\end{array}$} \\
\hline & Formas erosivas & & \\
\hline & Formas acumulativas & & \\
\hline \multirow{2}{*}{ Dinámica } & Procesos heredados & & \multirow{2}{*}{$\begin{array}{l}\text { Elementos heredados y funcionales } \\
\text { testigos de procesos pasados o activos }\end{array}$} \\
\hline & Procesos actuales & & \\
\hline \multicolumn{2}{|l|}{ Cronología } & & Fases o periodos \\
\hline \multicolumn{2}{|l|}{ Litología } & & Materiales presentes \\
\hline \multicolumn{2}{|c|}{ Estructuras geológicas } & & Número estructuras \\
\hline \multicolumn{2}{|c|}{ Estructuras sedimentarias } & & Número estructuras \\
\hline
\end{tabular}

Fuente: Serrano y González (2005).

La segunda evaluación, es de las características culturales, la cual toma en consideración todos los elementos culturales y ambientales referentes al geomorfositio, enriqueciendo los valores científicos que este posee (González, 2006). El valor máximo de esta evaluación es de 70, pero se expresan sus valores de 0 a 10 para compararlos con las otras evaluaciones (De Jesús, 2014). En la Tabla 2, se enumeran los valores evaluados en las características culturales. 
Dennis Pérez-Umaña,. Adolfo Quesada-Román. Methodology for evaluating and assessing geomorphosites in Costa Rica

Tabla 2: Componentes de la evaluación de las características culturales de los geomorfositios

\begin{tabular}{|c|c|c|c|}
\hline \multicolumn{2}{|c|}{ Evaluación } & Puntos & Definición \\
\hline \multicolumn{2}{|c|}{ Paisajístico y cultural } & Máximo 10 & $\begin{array}{l}\text { Consideración escalar paisajística } \\
\text { y estética: No existe (0), } \\
\text { Componente muy local y puntual } \\
\text { (2), Componente a escala media } \\
\text { (municipio) (4), Componente } \\
\text { comarcal (6), Componente esencial } \\
\text { del paisaje en amplios panoramas } \\
\text { (regional) (8), Elemento protegido } \\
\text { o gestionado por sus contenidos } \\
\text { paisajísticos (10). }\end{array}$ \\
\hline \multirow[t]{3}{*}{$\begin{array}{l}\text { Elementos } \\
\text { culturales }\end{array}$} & $\begin{array}{l}\text { Asociación a } \\
\text { elementos de valor } \\
\text { patrimonial }\end{array}$ & Máximo 10 & $\begin{array}{l}\text { Elementos patrimoniales } \\
\text { (monumentos, yacimientos, } \\
\text { poblaciones, construcciones } \\
\text { populares, elementos etnológicos, } \\
\text { entre otros). }\end{array}$ \\
\hline & Contenido cultural & Máximo 10 & $\begin{array}{l}\text { Aspectos culturales (mitos, } \\
\text { leyendas, literatura, pintura, otros). }\end{array}$ \\
\hline & Contenido histórico & Máximo 10 & Fases históricas de uso u ocupación. \\
\hline \multirow{2}{*}{$\begin{array}{l}\text { Elementos } \\
\text { educacionales }\end{array}$} & $\begin{array}{l}\text { Recursos } \\
\text { pedagógicos }\end{array}$ & Máximo 5 & $\begin{array}{l}\text { Contenidos pedagógicos y } \\
\text { docentes. }\end{array}$ \\
\hline & Niveles pedagógicos & Máximo 5 & $\begin{array}{l}\text { Primaria, secundaria, superior, } \\
\text { adultos, investigación. }\end{array}$ \\
\hline \multirow{2}{*}{$\begin{array}{l}\text { Elementos } \\
\text { científicos }\end{array}$} & Valor científico & Máximo 5 & $\begin{array}{l}\text { Áreas científicas con valor } \\
\text { significativo. }\end{array}$ \\
\hline & $\begin{array}{l}\text { Representatividad } \\
\text { científica }\end{array}$ & Máximo 5 & $\begin{array}{l}\text { Local (1), distrital (2), regional (3), } \\
\text { nacional (4), internacional (5). }\end{array}$ \\
\hline \multirow{2}{*}{$\begin{array}{l}\text { Elementos } \\
\text { turísticos }\end{array}$} & $\begin{array}{l}\text { Contenidos turísticos } \\
\text { reales }\end{array}$ & Máximo 5 & $\begin{array}{l}\text { Histórico artístico; activo } \\
\text { (excursionista, otros); paisajístico; } \\
\text { esparcimiento, relajación; otros. }\end{array}$ \\
\hline & $\begin{array}{l}\text { Potencial de } \\
\text { atracción turística }\end{array}$ & Máximo 5 & $\begin{array}{l}\text { Capacidad de atracción turística: } \\
\text { local, distrital, regional, nacional, } \\
\text { internacional. }\end{array}$ \\
\hline
\end{tabular}

Fuente: Serrano y González (2005).

La tercera evaluación, corresponde a las características de uso y gestión, la cual toma en consideración los componentes territoriales y el potencial de uso que tienen los geomorfositios, basándose en el conocimiento 
detallado de la geología y geomorfología de estos, así como en el trabajo de campo realizado en el área de estudio (González, 2006). La sumatoria obtenida es de 18 , el cual se expresa de 0 a 10 para compararlo con las otras evaluaciones. En la Tabla 3, se muestran los valores que se consideran en esta evaluación.

Tabla 3: Componentes de la evaluación de las características de uso y gestión

\begin{tabular}{|c|c|c|}
\hline Evaluación & Puntos & Definición \\
\hline \multirow{3}{*}{ Accesibilidad } & ALTO: 2. Buena accesibilidad & \multirow{3}{*}{$\begin{array}{l}\text { Facilidad de acceso a un } \\
\text { geomorfositio para su uso y } \\
\text { manejo }\end{array}$} \\
\hline & MEDIO: 1. Difícil accesibilidad & \\
\hline & BAJO: 0. Mala accesibilidad & \\
\hline \multirow{3}{*}{ Fragilidad } & ALTO: 0. Uso no recomendado & \multirow{3}{*}{$\begin{array}{l}\text { Grado de fragilidad del } \\
\text { geomorfositio debido a sus } \\
\text { características intrínsecas }\end{array}$} \\
\hline & MEDIO: 1. Uso Potencial & \\
\hline & BAJO: 2. Alto valor de uso & \\
\hline \multirow{3}{*}{ Vulnerabilidad } & $\begin{array}{l}\text { ALTO: } 0 \text {. Elementos capaces de } \\
\text { transformar la estructura o dinámica del } \\
\text { geomorfositio }\end{array}$ & \multirow{3}{*}{$\begin{array}{l}\text { Elementos del ambiente } \\
\text { del geomorfositio que } \\
\text { pueden entablar cambios } \\
\text { irreversibles en los valores } \\
\text { científicos y culturales }\end{array}$} \\
\hline & $\begin{array}{l}\text { MEDIO: 1. Transformación de bajo } \\
\text { grado }\end{array}$ & \\
\hline & BAJO: 2. No hay vulnerabilidad & \\
\hline \multirow{3}{*}{ Intensidad de uso } & $\begin{array}{l}\text { ALTO: } 0 \text {. Uso intenso, no permitiendo } \\
\text { cualquier incremento en las actividades }\end{array}$ & \multirow[t]{3}{*}{$\begin{array}{l}\text { Uso actual del } \\
\text { geomorfositio }\end{array}$} \\
\hline & MEDIO: 1. Uso moderado & \\
\hline & BAJO: 2. Bajo nivel de uso & \\
\hline \multirow{3}{*}{$\begin{array}{l}\text { Riesgo de } \\
\text { degradación }\end{array}$} & ALTO: 0. Alto riesgo de degradación & \multirow{3}{*}{$\begin{array}{l}\text { Posibles daños del } \\
\text { geomorfositio que causen } \\
\text { pérdida de valores } \\
\text { científicos y culturales }\end{array}$} \\
\hline & $\begin{array}{l}\text { MEDIO: 1. Riesgo moderado de } \\
\text { degradación }\end{array}$ & \\
\hline & BAJO: 2. Bajo riesgo de degradación & \\
\hline \multirow{3}{*}{$\begin{array}{l}\text { Estado de } \\
\text { Conservación }\end{array}$} & ALTO: 2 . Buen estado de conservación & \multirow{3}{*}{$\begin{array}{l}\text { Grado de conservación de } \\
\text { los valores científicos y } \\
\text { culturales del geomorfositio }\end{array}$} \\
\hline & $\begin{array}{l}\text { MEDIO: } 1 . \text { Estado moderado de } \\
\text { conservación }\end{array}$ & \\
\hline & BAJO: 0 . Mal estado de conservación & \\
\hline \multirow{3}{*}{ Impactos } & $\begin{array}{l}\text { ALTO: } 0 \text {. No se recomienda su uso, pero } \\
\text { se busca su restauración. }\end{array}$ & \multirow{3}{*}{$\begin{array}{l}\text { Elementos humanos que } \\
\text { afectan directamente el } \\
\text { geomorfositio (carreteras, } \\
\text { obras civiles) }\end{array}$} \\
\hline & $\begin{array}{l}\text { MEDIO: } 1 \text {. Uso permitido, pero se busca } \\
\text { orientarlo a su restauración. }\end{array}$ & \\
\hline & BAJO: 2. No hay impactos considerables & \\
\hline
\end{tabular}


Dennis Pérez-Umaña,. Adolfo Quesada-Román. Methodology for evaluating and assessing geomorphosites in Costa Rica

\begin{tabular}{|c|c|c|}
\hline Evaluación & Puntos & Definición \\
\hline \multirow{3}{*}{$\begin{array}{l}\text { Condiciones de } \\
\text { observación }\end{array}$} & $\begin{array}{l}\text { ALTO: } 2 \text {. Buenas condiciones de } \\
\text { observación }\end{array}$ & \multirow{3}{*}{$\begin{array}{l}\text { Condiciones de observación } \\
\text { (paisaje, ubicación, acceso, } \\
\text { entre otros) para el uso del } \\
\text { geomorfositio }\end{array}$} \\
\hline & $\begin{array}{l}\text { MEDIO: } 1 . \text { Calidad media de } \\
\text { observación }\end{array}$ & \\
\hline & $\begin{array}{l}\text { BAJO: } 0 \text {. Malas condiciones de } \\
\text { observación }\end{array}$ & \\
\hline \multirow{3}{*}{$\begin{array}{l}\text { Límite de cambio } \\
\text { aceptable }\end{array}$} & $\begin{array}{l}\text { ALTO: } 2 \text {. Baja fragilidad y débil } \\
\text { intensidad de uso, cambios no implican } \\
\text { pérdida de valores }\end{array}$ & \multirow{3}{*}{$\begin{array}{l}\text { Potencial de cambios } \\
\text { que puede asumir el } \\
\text { geomorfositio sin perder } \\
\text { sus valores científicos y } \\
\text { culturales. Se relaciona con } \\
\text { la fragilidad y la intensidad } \\
\text { de uso. }\end{array}$} \\
\hline & $\begin{array}{l}\text { MEDIO: } 1 \text {. La fragilidad y usos actuales } \\
\text { permiten cambios moderados sin pérdida } \\
\text { de valores }\end{array}$ & \\
\hline & $\begin{array}{l}\text { BAJO: } 0 \text {. Alta fragilidad o intensidad de } \\
\text { usos no permite cambio alguno sin que } \\
\text { se den pérdida de valores. }\end{array}$ & \\
\hline
\end{tabular}

Fuente: Serrano y González (2005).

Luego de realizar las tres evaluaciones se procede a realizar una evaluación global, la cual corresponde al promedio de las tres evaluaciones anteriores, donde se interpretan de manera global las características de cada geomorfositio en un solo conjunto, para determinar los atractivos y su importancia (Pérez, 2017). La clasificación para los geomorfositios de acuerdo a los valores obtenidos se observa en la Tabla 4.

Tabla 4: Clasificación de los geomorfositios de acuerdo a su evaluación

\begin{tabular}{|c|c|c|c|c|}
\hline Muy Baja & Baja & Media & Alta & Muy Alta \\
\hline $0-2$ & $2-4$ & $4-6$ & $6-8$ & $8-10$ \\
\hline
\end{tabular}

Fuente: Pérez (2017), basado en Serrano y González (2005).

\section{Resultados}

Para el Parque Nacional Volcán Poás, fueron evaluados 5 geomorfositios, los cuales fueron: Cráter Principal, Cono Botos, Cono Von Frantzius, Volcán Congo y Relicto Caldérico (Pérez, 2017), los cuales son formas del relieve atractivas dentro del Parque Nacional Volcán Poás (Figura 1). Los resultados obtenidos en las evaluaciones de los 5 geomorfositios se muestran en la Tabla 5. 


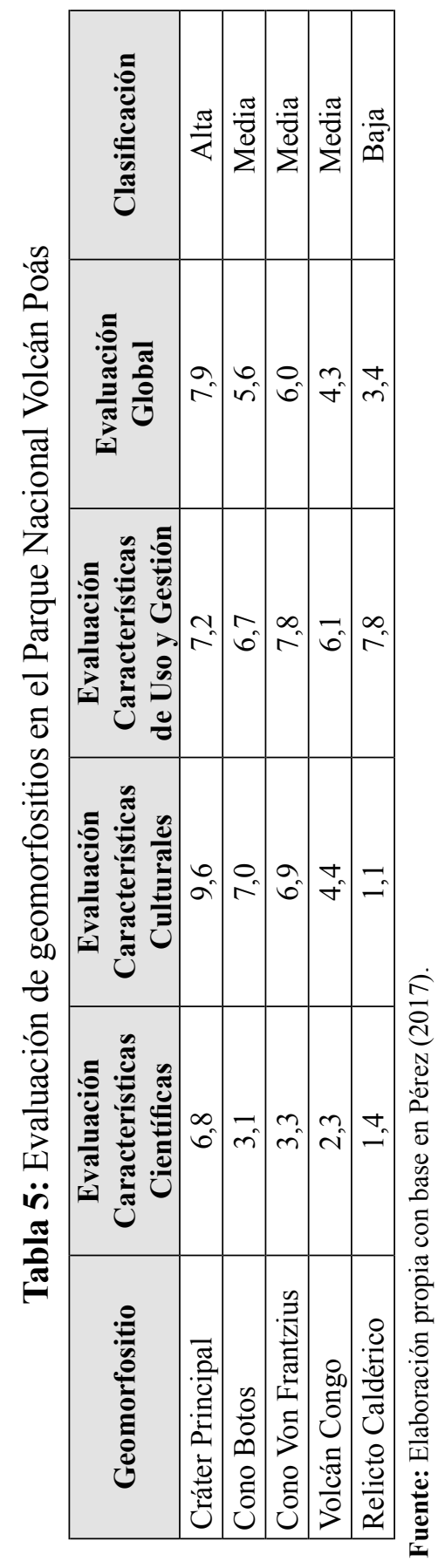


Dennis Pérez-Umaña,. Adolfo Quesada-Román. Methodology for evaluating and assessing geomorphosites in Costa Rica

Figura 1: Geomorfositios del Parque Nacional Volcán Poás

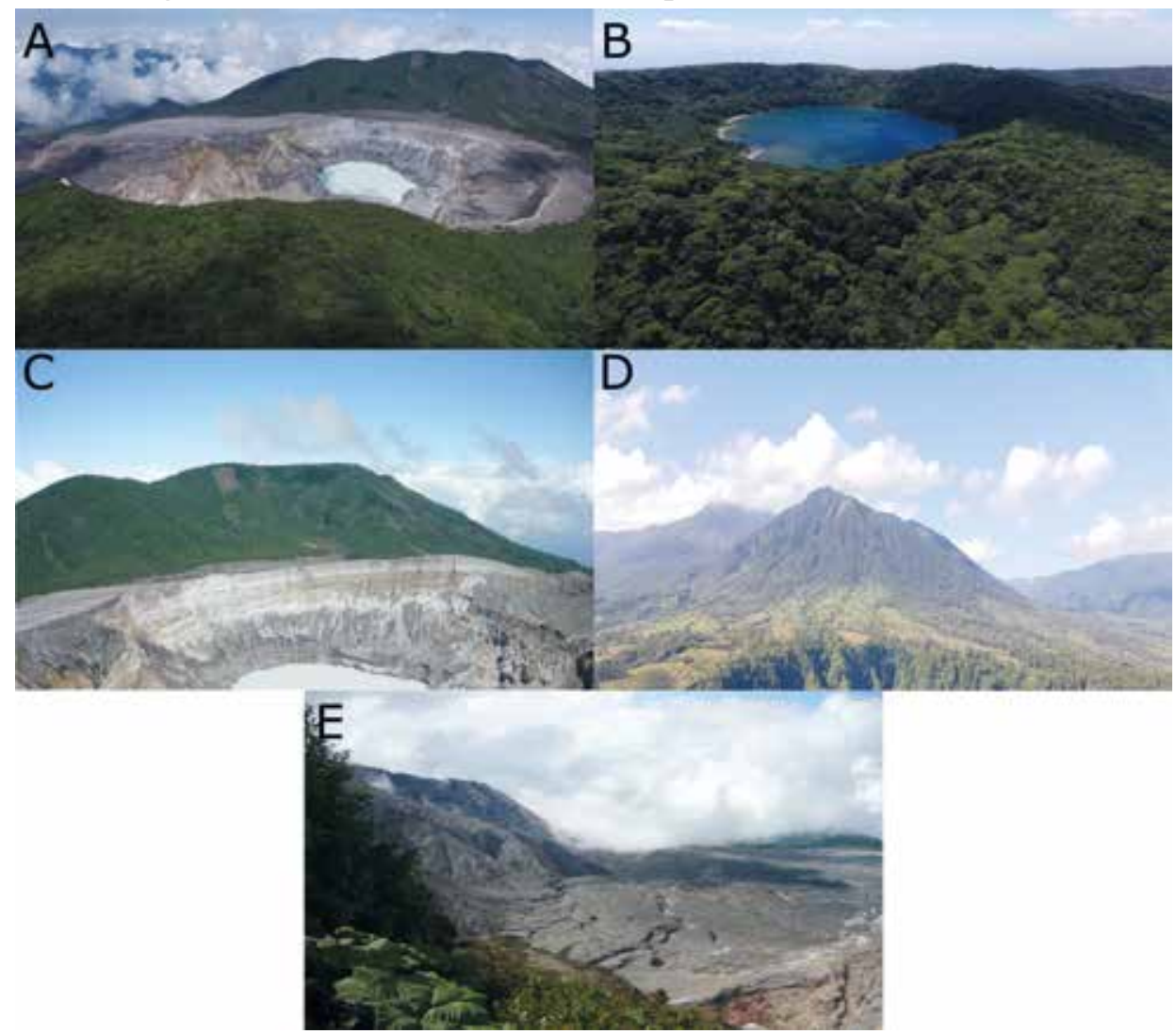

A) Cráter Principal (Fuente: PRIAS-CeNAT, 2017),

B) Cono Botos (Fuente: PRIAS-CeNAT, 2017),

C) Cono Von Frantzius (Fuente: propia, 2017),

D) Volcán Congo (Fuente: Martínez, 2017),

E) Relicto Caldérico (Fuente: propia, 2017).

La evaluación revela que el Cráter Principal es el geomorfositio que obtiene la evaluación más alta en las características científicas con valor de 6,8. Esto debido a que es el geomorfositio más complejo del volcán, además de ser el sitio de mayor actividad del macizo, cuyo origen se dio mediante una fuerte erupción, la cual modela la forma actual del geomorfositio, junto a otros procesos como la desgasificación (Pérez, 2017). El segundo en importancia es el Cono Von Frantzius con una valoración de 
3,3, donde su morfología actual se vio influenciada por la erupción que originó el Cráter Principal, la cual destruyó la mitad del cono (Pérez, 2017).

El Cono Botos obtuvo un valor de 3,1. Este geomorfositio no se vio tan afectado por la creación del Cráter Principal, aunque tuvo un periodo efusivo en sus orígenes (Pérez, 2017). Su importancia radica en la existencia de la Laguna Pluvial en su interior, así como que es en este geomorfositio donde se localiza la máxima altitud del Parque Nacional. El Volcán Congo obtuvo una valoración de 2,3. Dicho volcán tiene una forma cónica, cuyo único remanente posterior a su actividad fue la abertura de su cono, además que su actividad fue muy corta. Mientras que el geomorfositio Relicto Caldérico obtuvo en su evaluación un valor de 1,4, debido a que es muy pobre en su geología y geomorfología por no presentar muchas formaciones, pero se destaca que los materiales que lo conforman son parte de la Unidad Andesitas La Paz, una de las más antiguas formaciones del macizo (Ruiz et al., 2010).

En la evaluación de las características culturales fue el Cráter Principal el que obtuvo la valoración más alta con 9,6 , esto reflejado en la gran importancia cultural que tiene el geomorfositio, donde múltiples obras han sido inspiradas en este, además, tiene amplios paisajes que permiten no solo apreciar el geomorfositio, sino también el panorama circundante al volcán. Es un sitio muy visitado por el hecho de ser un volcán activo, lo cual aumenta su visitación por existir una fascinación hacia procesos activos del relieve (Dóniz et al., 2010), denotando que hay una relación entre los procesos sociales con la historia natural del volcán (De Jesús, 2014).

Los geomorfositios Cono Botos y Cono Von Frantzius obtuvieron una valoración de 7,0 y 6,9, respectivamente. La razón por la que ambos geomorfositios obtuvieron esta valoración se debe a la cercanía que tienen con el Cráter Principal, por lo que el turista que llega al Parque Nacional podrá observarlos en su visita, además que en todas las manifestaciones culturales basadas en el volcán estos dos geomorfositios también aparecen, como en el caso de la estampilla de 140 colones, donde aparece el Cráter Principal y el Cono Botos junto con su Laguna (Pérez, 2017).

Se debe destacar, que a nivel científico hayan sido investigados por naturalistas reconocidos en la historia costarricense, en el caso del Cono Von Frantzius recibe su nombre de Alexander Von Frantzius, quien investigó este volcán, así como de Henri Pittier, quien también realizó estudios 
Dennis Pérez-Umaña,. Adolfo Quesada-Román. Methodology for evaluating and assessing geomorphosites in Costa Rica

en el volcán y se enamoró de la Laguna Botos, y que Alvarado (2011) indica, que este científico en sus escritos expresaba el aprecio que tuvo hacia esta laguna.

Por otra parte, los geomorfositios Volcán Congo y Relicto Caldérico obtuvieron valores de 4,4 y 1,1 respectivamente, ambos obtuvieron valoraciones bajas debido a que no son tan conocidos por la población, a excepción del Volcán Congo, ya que la población que vive en sus cercanías lo logra identificar, pero para otras personas puede aparentar ser una montaña más de la cordillera, aunque este tenga un atractivo paisajístico por su cráter abierto (Pérez, 2017). Mientras que el Relicto Caldérico no es conocido por la población, lo cual no genera ningún tipo de aprecio o inspiración.

La evaluación de Uso y Gestión demuestra que todos los geomorfositios obtienen valores altos. En esta evaluación destacan los geomorfositios Cono Von Frantzius y Relicto Caldérico con 7,8. Ambos se encuentran en áreas donde los turistas no pueden tener acceso, por lo que se encuentran bien conservados. El que más llama la atención es el Relicto Caldérico, ya que en las evaluaciones anteriores obtuvo valores muy bajos, pero en esta destaca por su buen estado de conservación, incluso puede ser un potencial atractivo turístico del Parque Nacional (Pérez, 2017). Misma situación tiene el Cono Von Frantzius, el turista puede apreciarlo por su cercanía con el Cráter Principal, pero no tiene contacto directo con este, por lo que se mantiene en buen estado de conservación y no recibe un impacto severo de las personas.

Por otra parte, el Cráter Principal obtuvo una valoración de 7,2, pero a diferencia de los geomorfositios mencionados anteriormente, la población entra en contacto con el sitio directamente por lo que puede sufrir algún cambio en su estructura o sufrir un impacto que lo afecte. El volcán Poás es uno de los pocos volcanes que tiene una carretera que llega hasta el cráter (Zúñiga, 2008), facilitando el acceso a los miles de turistas que ingresan a este Parque Nacional, pero al mismo tiempo pueden generar un impacto en la morfología del Cráter.

En esta evaluación los geomorfositios Cono Botos y Volcán Congo obtuvieron las evaluaciones más bajas con 6,7 y 6,1 , respectivamente. El Cono Botos al igual que el Cráter Principal es muy visitado por lo que es vulnerable a un eventual cambio en su morfología, debido a la facilidad 
de accesos que provoca que muchas personas lo visiten. Mientras que el Volcán Congo esta inaccesible para los visitantes, este es vulnerable a sufrir cambios en su estructura por procesos naturales, recordando que es vulnerable a procesos de laderas que cambian su estructura. Además, no tiene accesos para que los turistas se acerquen al sitio, por lo que puede ser apreciado, únicamente, desde lejos (Pérez, 2017).

Por medio de la valoración global, se determina que el geomorfositio más importante del Parque Nacional Volcán Poás es el Cráter Principal, el cual tiene una valoración de 7,9. Al tener una diversidad geológica y una representación cultural muy significativa le dan un atractivo para que la población pueda aprender más de este geomorfositio, además, tiene condiciones óptimas para que los turistas puedan trasladarse al Cráter Principal (Pérez, 2017). El Cono Von Frantzius obtuvo una evaluación global de 6,0, en la que influyó mucho tener una morfología modificada por la actividad del Cráter Principal, además, que en la evaluación cultural así como en uso y gestión obtuvo valores altos, denotando que tiene cierta importancia cultural, además que al estar bien cuidado el geomorfositio lo hace un atractivo más del Parque Nacional.

Mientras que el Cono Botos obtuvo una evaluación global de 5,6, siendo la evaluación cultural más resaltante, ya que gran parte de los atributos culturales que tiene el geomorfositio son gracias a su cercanía con el Cráter Principal, esta evaluación se debe a que es tomado en cuenta en narraciones y manifestaciones artísticas. El Volcán Congo obtuvo un valor global de 4,3, siendo las características de Uso y Gestión las más destacadas, ya que es un geomorfositio que está bien conservado, pero que, por factores propios de la dinámica terrestre este puede variar su morfología. Tiene poca relación cultural y al mismo tiempo tiene poca diversidad geológica, pero aun así tiene características que son atractivas para el turista.

El Relicto Caldérico obtiene la evaluación global más baja con 3,4. En la evaluación científica y cultural obtiene valores muy bajos por tener una pobre riqueza geológica, así como no ser importante para la cultura costarricense, pero en la evaluación de uso y gestión obtiene altos valores, esto indica que es un potencial atractivo turístico para el parque nacional. 
Dennis Pérez-Umaña,. Adolfo Quesada-Román. Methodology for evaluating and assessing geomorphosites in Costa Rica

\section{Discusión}

La metodología de evaluación de geomorfositios consiste en hacer una triple comparación entre todos los valores que tiene uno de estos sitios, para luego promocionarlos de acuerdo a las características que estos poseen. Se pretende que un geomorfositio pueda ser aprovechado por la población, de manera que conozcan sobre este no solo porque sea un atractivo turístico más, sino que desde sus propias características pueda darse un conocimiento.

Al comparar estas características entre sí, se permite conocer cuál es el uso que se le puede dar el geomorfositio. Por ejemplo, el geomorfositio Cráter Principal al tener altos valores en la evaluación científica y cultural se propone que debe dársele un uso educativo, de investigación y de apreciación paisajística (Pérez, 2017), sin dejar de lado que se le dé un uso turístico, con el cual el visitante pueda utilizar estos valores para un aprendizaje, es decir, que sea un turismo con un enfoque más académico.

Una ventaja de esta metodología es que puede ser utilizada en diversas áreas, no solo en áreas silvestres protegidas, también puede utilizarse en otros territorios, como corredores biológicos, cantones, cuencas hidrográficas, entre otros, donde la variable de la diversidad geológica se considere necesaria para la protección de esta como un recurso de un determinado territorio.

A nivel turístico la metodología permite reconocer nuevos valores a los atractivos turísticos de un territorio. En el caso mostrado en este estudio en el Parque Nacional Volcán Poás, sale a la luz información existente de un geomorfositio, que los turistas desconocen, por ejemplo, el caso de una leyenda, alguna canción o un texto, valores culturales agregados al geomorfositio que ayudan al turista a tener una mejor noción del sitio que visita, destacando que este no tiene solo un paisaje que llama la atención, sino que detrás se pueden mencionar una serie de valores agregados, porque el sitio que visitan es importante para la población local.

\section{Conclusiones}

- Se presentó una metodología práctica, fácil de aplicar, novedosa y útil para evaluar, valorar y clasificar lugares de interés geológico, a partir del conocimiento de sus características geofísicas, culturales, socioeconómicas y de uso y gestión. 
- La metodología permite conocer y darle interés al contenido científico y cultural del geomorfositio, donde se busca identificar cuál tiene una mayor relevancia.

- Pese a que se trata de información que se puede considerar subjetiva, como es el caso de las características culturales, esta metodología propone como contabilizar esas características, que en un inicio pueden ser consideradas como incontables.

- La metodología puede ser empleada en cualquier tipo de relieve, ya sea volcánico, costero o glaciar. Además, que puede ser utilizada en otros territorios, como, por ejemplo, en los cantones con miras a su aplicación en el ordenamiento territorial.

- Se utilizó el ejemplo particular del volcán Poás, ya que es el volcán más estudiado por científicos tanto nacionales como internacionales, hasta abril de 2017 anterior a su reactivación, era el volcán más visitado del país con visitación superior a 200 mil personas al año.

- $\quad$ Es el primer estudio de geomorfositios para Costa Rica, se pretende ser la base para futuros estudios en áreas de conservación, sitios a escalas político-administrativas como provincias, cantones o distritos, así como unidades naturales como cuencas hidrográficas, volcanes, cerros, u otros lugares de interés. Por tanto, se insta a la aplicación de esta metodología para un mayor conocimiento de los recursos naturales y su difusión turística responsable.

\section{Referencias}

Alvarado, G. (2011). Los volcanes de Costa Rica: geología, historia, riqueza natural y su gente. San José, Costa Rica: EUNED.

Alvarado, G. (agosto de 2013). Los volcanes han influido en la cultura y el arte de Costa Rica. La Nación. Recuperado de http:// www.nacion.com/ocio/artes/volcanes-influido-cultura-Costa-Rica_0_1360663943.html

Alvarado, G., \& Salani, F. (2004). Tefroestratigrafía (40000-2000 a.P.) en el sector Caribe de los volcanes Barva, Congo y Hule, Cordillera Central, Costa Rica. Revista Geológica de América Central, (30), $59-72$.

Ceruti, M. (2010). Los volcanes sagrados en el folclore y la arqueología de Costa Rica. Mitológicas, 25, $39-50$. 
Dennis Pérez-Umaña,. Adolfo Quesada-Román. Methodology for evaluating and assessing geomorphosites in Costa Rica

Chaves, F. (noviembre de 2014). Canción "A la Sombra del Poás" resalta las tradiciones y paisajes de Alajuela. La Nación. Recuperado de http://www.nacion.com/ocio/musica/Cancion-resalta-tradicionespaisajes-Alajuela_0_1453654634.html

Comanescu, L. \& Nedelea A. (2010). Analysis of some representative geomorphosites in the Bucegi Mountains: between scientific evaluation and tourist perception. Area (4), 406 - 416. doi 10.1111/j.1475-4762.2010.00937.x

Coratza, P., Ghinoi, A., Piacentini, D. \& Valdati, J. (2008). Management of geomorphosites in high tourist vocation area: an example of geo-hiking maps in the Alpe Di Fanes (Natural Park of Fanes-SenesBraies, Italian Dolomites). GeoJournal of Tourism and Geosites. 2, (2), 106-117.

Costa, F. (2011). Volcanic geomorphosites assessment of the last eruption, on April to May 1995, within the natural park of Fogo Island, Cape Verde. GeoJournal of Tourism and Geosites. 8, (2), 167-177.

De Jesús, J. (2014). Geomorfositios en el volcán Paricutín, Michoacán, México (Tesis de licenciatura). Universidad Nacional Autónoma de México, México D.F.

Dóniz, J., Guillén, C., Becerra, R., \& Kereszturi, G. (2010). Volcanes y turismo, Patrimonio, atractivo, recurso y producto. Turismo. 2, 73-79.

[Fotografía de Andrés Barahona Contreras]. (Parque Nacional Volcán Poás, 16 de febrero de 2017). Archivos. PRIAS-CeNAT, San José, Costa Rica.

[Fotografía de Javier Martínez Quesada]. (Laguna Hule, 8 de marzo de 2017). Archivos. PROTOBA S.L., Costa Rica

González, J. (2006). El Macizo Central de los Picos de Europa: Geomorfología y sus implicaciones geoecológicas en la Alta Montaña Cantábri$c a$. (Disertación doctoral publicada). Departamento de Geografía, Urbanismo y Ordenación del Territorio, Universidad de Cantabria.

González, J. \& Serrano, E. (2008). La valoración del Patrimonio Geomorfológico en Espacios Naturales Protegidos. Su aplicación al Parque Nacional de los Picos de Europa. Boletín de la Asociación de Geógrafos Españoles. (47), 175 - 194.

Ilies, D. \& Josan, N. (2008). Some theoretical aspects regarding the genesis of geosites. GeoJournal of Tourism and Geosites. 1, (1), 7-12. 
Palacio, J. (2013). Geositios, geomorfositios y geoparques: importancia, situación actual y perspectivas en México. Investigaciones Geográficas, Boletín del Instituto Geográfico, UNAM. (82), 24-37.

Pérez, D. (2017). Evaluación del potencial turístico de geomorfositios en el Parque Nacional Volcán Poás (Tesis de Licenciatura en Ciencias Geográficas con énfasis en Ordenamiento del Territorio). Universidad Nacional de Costa Rica, Heredia, Costa Rica.

Quesada, A., \& Barrantes, G. (2016). Procesos de ladera cosísmicos del Terremoto de Cinchona (Costa Rica) del 8 de enero de 2009. Cuadernos de Geografia. Revista Colombiana de Geografia, 25 (1). 217 - 232.

Reynard, E. \& Panizza, M. (2005). Geomorphosites: definition, assessment and mapping. An Introduction. Géomorphologie: relief, processus, environment. (3). 177-180.

Ruiz, P., Gazel, E.,Alvarado, G., Carr, M.\& Soto, G. (2010). Caracterización geoquímica y petrográfica de las unidades geológicas del macizo del volcán Poás, Costa Rica. Revista Geológica de América Central. (43), $37-66$.

Salguero, M. (2003). Volcanes de Costa Rica. San José, Costa Rica: Editorial Costa Rica.

Serrano, E. \& González. J. (2005). Assessment of geomorphosites in natural protected areas: the Picos de Europa National Park (Spain). Géomorphologie: relief, processus, environment. (3). 197-208.

SINAC (Sistema Nacional de Áreas de Conservación). (2008). Plan de Manejo del Parque Nacional Volcán Poás. Recuperado de http:// www.sinac.go.cr/AC/ACCVC/volcanpoas/Documents/Plan\%20 de\%20Manejo\%20PNVP.pdf

SINAC (Sistema Nacional de Áreas de Conservación). (2016). SINAC en números: Informe Anual Estadístico 2015. San José, Costa Rica: SINAC.

Vargas, A. (2014). Aportes a la geomorfología, geología y vulcanología de Costa Rica por Alexander von Frantzius. Revista Geológica de América Central. (51), 129-136.

Vargas, G. (2014). Geografía de Costa Rica. San José, Costa Rica: EUNED. Zeledón, E. (1989). Leyendas costarricenses. San José, Costa Rica, Museo de Cultura Popular.

Zúñiga, R. (2008). Guía de Parques Nacionales de Costa Rica. Madrid: Jomagar 